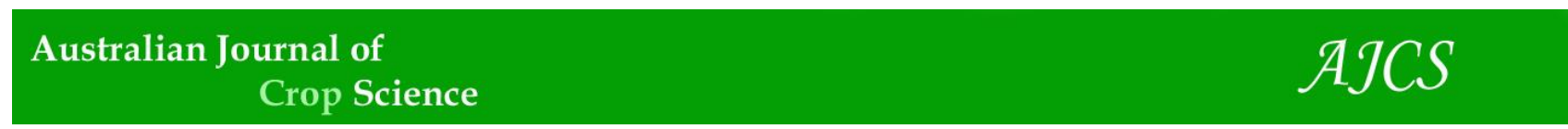

AJCS 12(02):185-192 (2018)

ISSN:1835-2707

doi: 10.21475/ajcs.18.12.02.pne477

\title{
Gluten-free puffed snacks of rice and cassava
}

\author{
Anna Cláudia Sahade Brunatti ${ }^{1}$, Emerson Loli Garcia ${ }^{2}$, Martha Maria Mischan ${ }^{3}$, Magali Leonel ${ }^{2 *}$ \\ ${ }^{1}$ Fatec, Marília, São Paulo State, Brazil \\ ${ }^{2}$ Center for Tropical Roots and Starches (CERAT), São Paulo State University (UNESP), Botucatu, São Paulo, Brazil \\ ${ }^{3}$ Department of Statistic, Bioscience Institute, São Paulo State University (UNESP), Botucatu, São Paulo, Brazil
}

\section{*Corresponding author: mleonel@cerat.unesp.br}

\begin{abstract}
The growing demand for gluten-free products in recent years has necessitated the quest for suitable raw materials. Rice flour and cassava starch are gaining interest in the gluten-free food industry because of their favorable characteristics. Apart from the intrinsic properties of the raw materials, industrial factors relating to the process, product quality, and sensory acceptance by the consumers are crucial for new product development. Here, we report the effect of extrusion temperature, screw speed, moisture, and amount of cassava starch in the rice flour mixture on the physical properties of gluten-free puffed snacks. Extrusion was carried out using a single-screw extruder in a central composite rotational design, which combines shear forces, high pressure, and high temperature in a short time. The extruded snacks were evaluated for the radial expansion index, specific volume, water absorption index, water solubility index, and hardness. Results showed that the amount (\%) of cassava starch in the rice flour mixture was a determinant factor in snack production. A low percentage of cassava starch (10\%) and moisture (14\%), along with lower temperature in the extrusion zone $(90 \stackrel{\circ}{ })$ and $233 \mathrm{rpm}$ screw speed, produced snacks with desirable characteristics such as high expansion, low density, good crispiness, light color, and low water solubility index. In addition, the snacks obtained under these conditions exhibited good sensory acceptance.
\end{abstract}

Keywords: Extrusion; Manihot esculenta; Oryza sativa.

Abbreviations: REI_expansion index; SV_specific volume; H_hardness; WSI_water solubility index; WAI_water absorption index; CS_cassava starch; T_temperature; $M_{-}$moisture; ns_non significant; $R^{2}$ determination coefficient.

\section{Introduction}

The celiac disease results from the body's intolerance to gliadin, a constituent of the gluten protein, which has a toxic effect on the small intestinal mucosa, resulting in the destruction of the intestinal villi and interfering with nutrient absorption. This damage occurs in susceptible people upon ingestion of wheat and cereals such as barley, rye, and oats. The only remedy prescribed for people with gluten intolerance is a gluten-free diet, which can minimize disease symptoms, thereby improving the quality of life and reducing the risk of mortality, even in asymptomatic patients (Arendt and Nunes, 2010; Torbica et al., 2010). The glutenfree food market has seen significant growth in recent years and has attracted media attention. The consumption of these products has not been only by consumers with celiac disease, but for various reasons, an increasing proportion of people come avoiding consuming products with gluten (Masure et al., 2016). A market analysis by MINTEL shows that $65 \%$ of the American consumers prefer gluten-free products to maintain good health, $27 \%$ of the respondents use them to lose weight, $11 \%$ consider them as a remedy to their prevailing health problems, and $20 \%$ for other reasons (Witczak et al., 2016). Cassava is cultivated in all states of Brazil, with outstanding importance in human and animal consumption (Leonel et al., 2009; Spinello et al., 2014).
Starch is the main product of cassava in terms of production volume and market value. Starch is thus being used widely in a diverse range of food products.

Outside the Asian continent, Brazil is the largest producer of rice. The harvested white rice is processed via precleaning, drying, cleaning, sorting, and packing. For every $100 \mathrm{~kg}$ of polished white rice, about 8 to $10 \mathrm{~kg}$ of broken rice is generated. With the increasing global production of white rice (40\% increase in demand until 2030$)$, the production of broken rice is also expected to increase (Khush, 2005, Setyawati et al., 2016). This trend has aroused a growing interest in the production of flour. The intrinsic characteristics as well as the strong social and economic appeal of cassava starch and rice flour indicate the potential application of the mixture of these substances for manufacturing gluten-free food products. This may trigger the production of these products in Brazil and other producing countries.

Extrusion is a continuous one-step process that combines shear forces, high pressure, and high temperature in a short time. In this process ingredients are subjected to mixing, heating, and shearing, and are forced to flow through a die for forming and expansion (Berk, 2009; Vargas-Solórzano et al., 2014; Salata et al., 2014). Although extrusion is widely 
used for the production of snacks, the characteristics of the raw material directly influence the growth and texture of puffed snacks (Moraru and Kokini, 2003). Several studies have used derivatives of cassava (Leonel et al., 2011; Taverna et al., 2012; Mesquita et al., 2013; Trombini et al., 2016); and rice flour in the development of extruded products (Ti et al., 2015; Wu et al., 2015; Awolu et al., 2015), which shows the potential application of mixtures of these substances as raw materials for gluten-free products.

This study was based on the following assumptions: there is a constant need for innovation in the food industries to meet the demands of consumers; there is a growing market for gluten-free products; both cassava starch and rice flour can be used as raw materials in the food industries; and the extrusion process is a low-cost technology that aids the manufacture of different products.

Thus, our study aims to analyze the chemical composition and physical characteristics of cassava starch and rice flour, evaluate the effects of different parameters pertaining to the extrusion process on the physicochemical properties of snacks, and analyze the acceptance of the product among consumers.

\section{Results and discussion}

\section{Analysis of raw materials}

The chemical composition of the raw materials is one of the important factors to be considered in the preparation of extruded products. Cassava starch shows a high percentage of total carbohydrates and low levels of ash, lipids, fibers, and protein. This product shows high luminosity, low solubility in water, and no cold viscosity, thus showing a high viscosity peak with low resistance to heat and agitation, and high setback (Table 1).

On the other hand, rice flour shows a high total carbohydrate content and significant protein content. This product has a light color, low solubility, and water absorption. It has no cold viscosity, with low peak viscosity, final viscosity, and setback (Table 1). The low concentration of non-starch components in the commercial product of cassava is in accordance with its intrinsic characteristics and implies the efficiency of the industrial starch extraction process on a large scale. The chemical composition of cassava starch samples (Table 1 ) is quite variable, as reported by Zhu (2015), with the ash content ranging from $0.03 \%$ to $0.29 \%$, protein content from $0.06 \%$ to $0.75 \%$, lipid content from $0.1 \%$ to $1.2 \%$, and fiber content from $0.11 \%$ to $1.9 \%$. Various factors affect the chemical composition and physicochemical properties of rice flour, including cultivars, amylose content, and production methods, as reported by $\mathrm{Yu}$ et al. (2012). Flour obtained from different types of rice contains $80.17 \%$ to $81.33 \%$ total carbohydrate content, $6.93 \%$ to $8.33 \%$ protein content, and $0.87 \%$ to $1.44 \%$ lipid content. The chemical composition of the rice flour used in this study (Table 1 ) is close to that reported by Wanyo et al. (2009), viz., $6.83 \%$ protein, $0.22 \%$ ash, $11.77 \%$ moisture, $0.21 \%$ lipids, and $80.35 \%$ total carbohydrates. Our results are also similar to those reported by Clerici and El-Dash (2008), i.e., $7.56 \%, 0.27 \%, 12.88 \%, 0.82 \%$, and $78.97 \%$ of protein, ash, moisture, lipids, and carbohydrates, respectively.
The cassava starch and rice flour showed similar patterns of color, with high luminosity $\left(L^{*} \approx 95\right)$ and the presence of red $\left(+a^{*}\right)$ and yellow $\left(+b^{*}\right)$ shades.

The low water solubility index (WSI) and water absorption index (WAI) of starchy raw products also were observed for cassava starch and rice flour. These indices depend on the chemical composition of the product and of the interactions between their constituents and water. Starch is insoluble in water. However, the water solubility of proteins is affected by the number of protein-protein and protein-water interactions. Hydrophobic interactions result in decreased solubility, while the ionic and polar forces allow better interactions between the protein and water molecules, thereby increasing the solubility of the former.

The WAl is associated with gel formation through the binding capacity of hydroxyl groups $(-\mathrm{OH})$ with water. The commercial cassava starch used in this experiment could contain a small amount of pregelatinized starch granules modified during the drying process, which may accelerate gel formation.

Cassava starch shows very low cold viscosity and high peak viscosity, indicating the integrity of the starch granules, low resistance to heat and agitation, and high retrogradation tendency (Table 1). The properties of starch paste are mainly dependent on the genotypes, cultivation conditions, and methods of extraction. Onitilo et al. (2007) studied forty genotypes of cassava and reported variations in the peak viscosity of starch from 261 to $593 \mathrm{RVU}$, breakdown from 141.2 to 329.0 , setback from 19 to $79.9 \mathrm{RVU}$, and pasting temperature ranging from 63.8 to $65.7^{\circ} \mathrm{C}$.

Rice flour shows lower peak viscosity, final viscosity, and retrogradation as compared to cassava starch (Table 1). Literature reports show that the pasting properties of rice starch vary among genotypes, but the starch has low peak viscosity, low resistance to heat and agitation, and low retrogradation. Ashogbon and Akintayo (2012) evaluated the properties of rice starch extracted from different cultivars and reported peak viscosity ranging from 176.33 to 279.69 RVU, breakdown from 40.92 to $52.50 \mathrm{RVU}$, final viscosity from 189.67 to $329.2 \mathrm{RVU}$, and setback from 50.08 to 102.5 $\mathrm{RVU}$, which indicates that the values observed for rice flour followed the same trend. In addition, rice flour has been reported to show poorer pasting properties than rice starch, suggesting that the proteins and lipids of rice flour influence the pasting properties because of the possible reaction between amylose and lipid or protein with starch (Yan et al., 2005; Yu et al., 2012; Tong et al., 2015).

\section{Characteristics of extruded products}

Extrusion cooking is an important processing technique in the food industry, which can be effectively used to develop novel products that might not be obtained through other processing methods. The expansion of extruded products (radial expansion index; REI) ranged from 3.10 to 8.02. Data analysis showed the effect of moisture content and the amount of cassava starch on this index. The model was predictive $\left(R^{2}=0.832\right.$, Lack of fit $\left.p>0.05\right)$ (Table 3$)$. As shown in the response surface drawn at high moisture and low concentration of cassava starch, the extruded products showed less expansion (Figure 1a). The expansion of the material is directly related to its moisture. Some studies have shown that the REI decreases significantly with 
increasing moisture content. Such results were reported by Clerice and El-Dash (2008) for rice flour extrusion and Chang and El-Dash (2003) for the extrusion of cassava starch. This phenomenon occurs due to the relationship between the amount of water and the strength of the gels formed during extrusion. The low moisture content in the mixtures and the low percentage of cassava starch may have restrained the flow inside the extruder. This increases the shear and residence time, which in turn increases the starch gelatinization degree and the expansion of the material (Figure 1a). At high moisture and high percentage of cassava starch, a higher REI was observed (Figure 1a). At higher moisture levels, more water is available for steam formation and expansion of the starch. This higher moisture content may also reduce the viscosity of the extrudate, making it more expandable by the steam. The lower viscosity and greater capacity for steam formation may jointly afford a greater number of cells with thin walls, producing an extrudate with a weak cellular structure that is susceptible to rupture and ultimate collapse (Salata et al., 2014).

The effect of protein-starch interaction at lower rice flour contents should also be considered. In general, increasing the protein content in the admixture with starch leads to a reduction in expansion (Allen et al., 2007).

Another aspect is the higher viscosity of the raw material at higher percentages of cassava starch in combination with rice flour, which could be attributed to the intrinsic characteristics of cassava starch. If the viscosity is too low, the gas will not be entrapped, resulting in an unexpanded product. On the other hand, if it is too high, the expansion will be limited (Moraru and Kokini, 2003; Witczak et al., 2016).

Specific volume (SV) is an important performance parameter of extruded puffed snacks. It is a measure of volumetric expansion, which is the sum of the radial and axial expansions (Salata et al., 2014). The SV of the extrudates ranged from 7.89 to $11.75 \mathrm{~mL} \mathrm{~g}^{-1}$. ANOVA results showed a linear variation in the SV with the cassava starch content and moisture $(p<0.05)$ (Table 2$)$. The $p$-value for lack of fit was not significant, as required $(p>0.05)$. The RSquared value was 0.825 . The surface plot presenting the effect of cassava starch and moisture on the SV is shown in Figure $1 \mathrm{~b}$. A low cassava starch content in the mixture and low moisture resulted in a higher SV i.e., lower density of the extruded product. A high moisture content in the raw material can reduce the elasticity of the mass through plasticization of the molten material, resulting in reduction of the specific mechanical energy and a consequent reduction in gelatinization. The observed changes in the SV (Figure $1 b$ ) could be attributed to the increase in the residence time in the extruder, which is caused by high cassava starch content and moisture, leading to degradation of the molecular structure of amylopectin. This caused a reduction in the radial expansion, resulting in higher density (Thymi et al., 2005).

The hardness of the extruded products is the maximum force required for a probe to penetrate the product, which ranged from 2.48 to $19.56 \mathrm{~N}$ ( 0.25 to $2 \mathrm{kgf})$. The influence of the independent variables on the hardness of the extruded product is summarized in Table 2 . The statistical results for the hardness showed that the model terms ( $M, M * M, S S * S S$ and $M * S S)$ were significant $(p<0.05)$. This indicates that the moisture and screw speed affected the hardness. The $p$ - value for lack of fit was 0.1185 , and the $\mathrm{R}$-squared value was 0.757. The surface plots showing the effect of the independent variables on hardness are illustrated in Figure 1c. The results showed that at high screw speed and moisture, the extruded products had higher hardness. The increase in water content caused a reduction in the viscosity of the dough, lower gelatinization of the starch, and slower growth of bubbles, thereby resulting in a denser product (Ding et al., 2005). Sumargo et al. (2016) also observed the effect of moisture on hardness in extrusion processing of brown rice and pinto bean composite flours. Increasing the moisture content increased the density and hardness but decreased the expansion. The effect of screw speed could be related to the material viscosity and die pressure. A higher screw speed leads to faster heating and higher shearing force, which in turn results in a decrease in viscosity as well as die pressure, thus yielding a harder product (Meng et al., 2010; Wang et al., 2016).

The color of the extruded products is an important quality parameter. The luminosity $\left(L^{*}\right)$ of the extruded products ranged from 82.17 to 90.75 . Data analysis showed a negative linear effect of cassava starch on $L^{*}$ (Table 2). The model was not significant, but the lack of fit was significant. On the other hand, the effect of the cassava starch and extrusion temperature on a* was observed with the adjusted Rsquared value of 0.7820 , and the lack of fit was not significant $(p>0.05)$. This indicates that the central condition of temperature and a higher cassava starch content in the mixture leads to higher $a^{*}$ (Figure $1 \mathrm{~d}$ ). The model obtained for the $b *$ value was not significant.

Color analysis of the extruded products showed the influence of the percentage of cassava starch in the mixture on the luminosity: extrudates with lower luminosity were obtained at higher percentages of cassava starch in the rice flour mixture. The increase in redness of the extruded products (Figure 1d) was attributed to the prolonged passage of the material in the extrusion barrel at higher cassava starch content, which could have promoted the degradation of the components favoring browning reactions. The WAl of the products ranged from 5.61 to $7.87 \mathrm{~g}_{\mathrm{gel}} \mathrm{g}^{-1}$. The model was significant, and the level of cassava starch in the blend and the extrusion temperature had a notable effect on the WAI (Table 2). The lack of fit was not significant ( $p>0.05)$, and the adjusted R-squared value was 0.805 . A higher WAI in the extruded products was obtained under processing conditions with low cassava starch contents in the blend and low extrusion temperatures (Figure 1e). The WAI is also related to absorbance and water retention by the constituents of the feedstock. During extrusion, the starch granules gelatinize and the proteins are denatured. The gelatinized starch absorbs more water than does natural starch, and the hydrophilic/hydrophobic balance of the proteins may be disturbed due to conformational and structural changes; these may contribute to an increase or decrease in the WAI. A low cassava starch content in the blend and low extrusion temperature favored the gelatinization of starch fraction and facilitated interactions between the protein and water molecules, thus increasing water absorption (Figure 1e).

Water solubility index is an indicator of starch degradation and describes the rate and the extent of dissolution of powder materials in water (Awolu et al., 2015). The extrusion process yielded products with considerable 
Table 1. Mean and standard deviation of the characteristics of raw materials.

\begin{tabular}{lcc} 
& Cassava starch & Rice flour \\
\hline Moisture (\%) & $14.0 \pm 0.16$ & $10.35 \pm 0.18$ \\
Ash (\%) & $0.17 \pm 0.01$ & $0.39 \pm 0.01$ \\
Lipids (\%) & $0.61 \pm 0.05$ & $0.97 \pm 0.02$ \\
Fiber (\%) & $0.40 \pm 0.03$ & $0.91 \pm 0.02$ \\
Protein (\%) & $0.21 \pm 0.01$ & $7.32 \pm 0.01$ \\
Total carbohydrates (\%) & $82.10 \pm 0.35$ & $80.06 \pm 0.69$ \\
L $^{*}$ & $95,81 \pm 0,18$ & $94,65 \pm 0,04$ \\
a* & $0,80 \pm 0,02$ & $0,95 \pm 0,01$ \\
b $^{*}$ & $4,04 \pm 0,06$ & $4,40 \pm 0,05$ \\
Water solubility index (\%) & $1,52 \pm 0,07$ & $2,36 \pm 0,07$ \\
Water absorption index ( g gel g ${ }^{-1}$ ) & $3,62 \pm 0,07$ & $2,2 \pm 0,01$ \\
Cold viscosity (RVU) & $0,97 \pm 0,06$ & $1,11 \pm 0,06$ \\
Peak of viscosity (RVU) & $425,80 \pm 36,79$ & $228,78 \pm 17,67$ \\
Breakdown (RVU) & $257,75 \pm 34,82$ & $47,42 \pm 0,35$ \\
Final viscosity (RVU) & $368,08 \pm 25,42$ & $209,09 \pm 2,71$ \\
Setback (RVU) & $200,0 \pm 25,8$ & $17,54 \pm 0,65$ \\
\hline
\end{tabular}

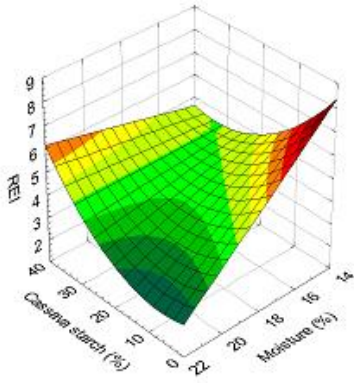

(a)

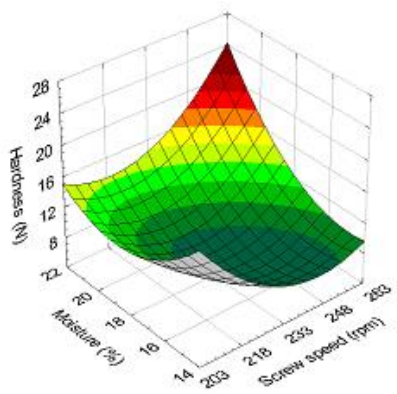

(c)

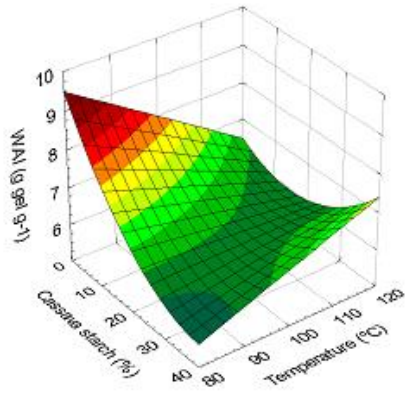

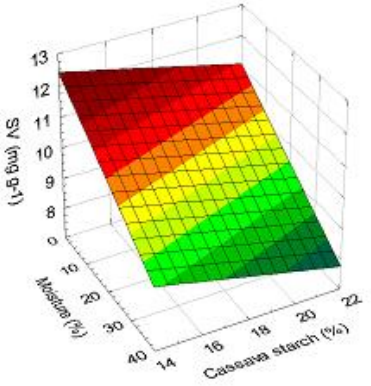

(b)
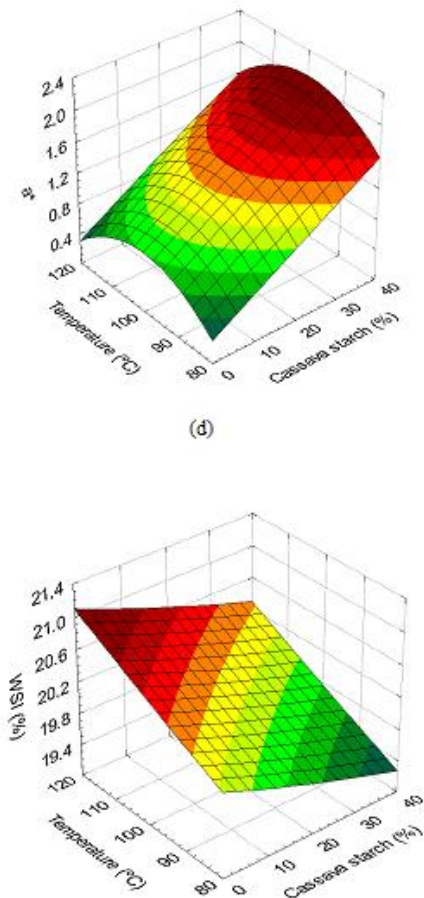

Fig 1. Effects of variable parameters of extrusion processing on radial expansion index (REI) (a), specific volume (SV) (b), hardness (c), a* (d), water absorption index (WAI) (e) and water solubility index (WSI) (f) of snacks. 
Table 2. Regression coefficients of dependent variables of extrusion process.

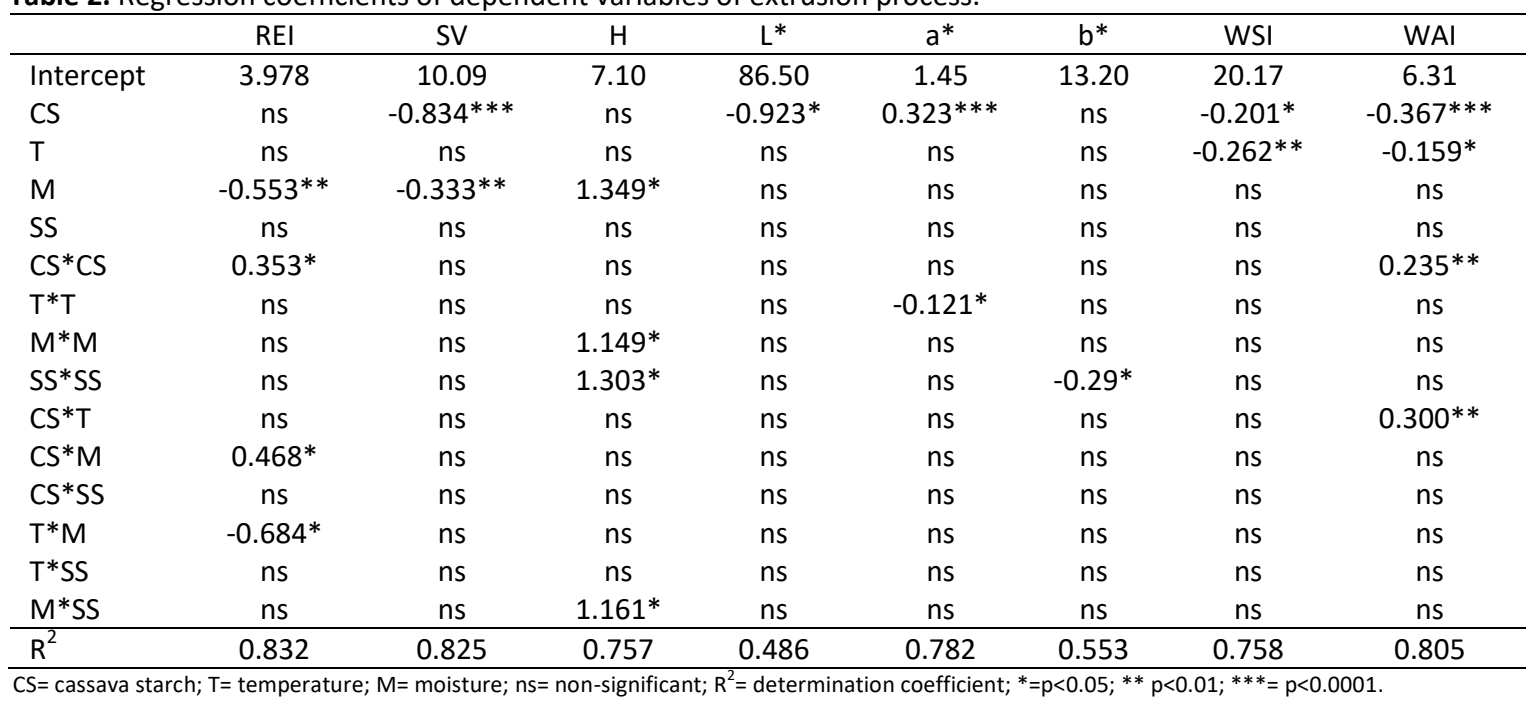

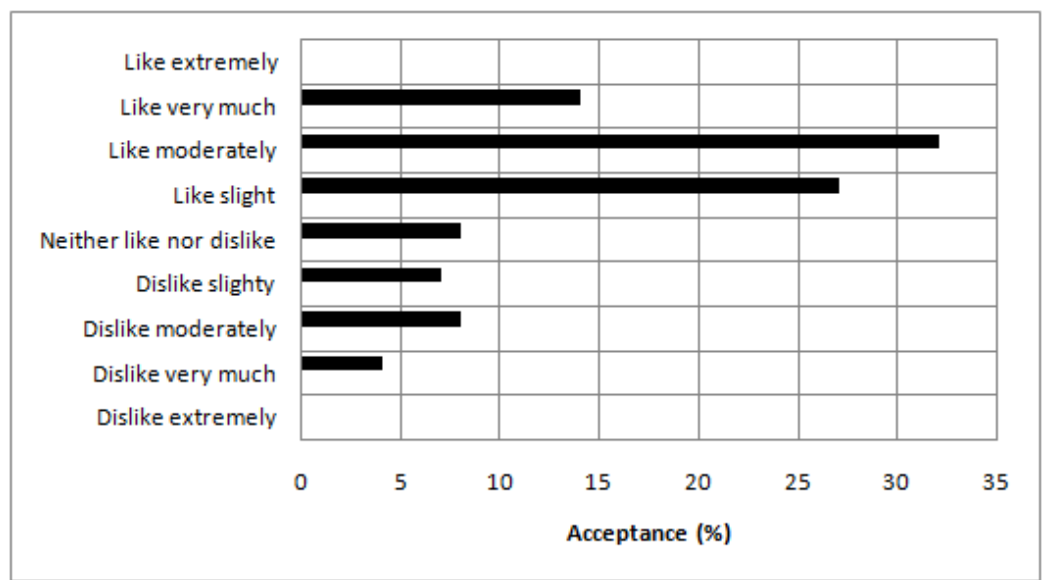

Fig 2. Sensorial acceptance of snacks.

Table 3. Variables parameters of extrusion and levels of variation.

\begin{tabular}{|c|c|c|c|c|c|}
\hline \multirow[b]{2}{*}{ Independent variables } & \multicolumn{5}{|c|}{ Levels of variation } \\
\hline & $-\alpha$ & -1 & 0 & +1 & $+\alpha$ \\
\hline Cassava starch (\%) & 0 & 10 & 20 & 30 & 40 \\
\hline Temperature $3^{\text {rd }}$ zone $(\stackrel{\circ}{ } \mathrm{C})$ & 80 & 90 & 100 & 110 & 120 \\
\hline Moisture (\%) & 14 & 16 & 18 & 20 & 22 \\
\hline Screw speed (rpm) & 203 & 218 & 233 & 248 & 263 \\
\hline
\end{tabular}

solubility in water, with WSI varying from $11.16 \%$ to $25.88 \%$. Data analysis showed effects of the percentage of cassava starch in the blend and the extrusion temperature on the WSI (Table 2). The model was not significant, the adjusted Rsquared value was 0.74 , and the lack of fit was not significant. The drawn surface showed that at low temperature and higher percentage of cassava starch, the solubility of the products decreased (Figure 1f). This result is consistent with that obtained for the WAl, showing low degradation of the starchy fraction and a possible increase in the interaction of gelatinized starch with other components of the feedstock, thereby decreasing the water solubility. In general, a high expansion index, low bulk density, and firm texture are the desirable characteristics of extrusion products (Masatcioglu et al., 2014). The results showed that these desirable characteristics can be achieved at low percentage of cassava starch (10\%), low moisture (16\%), low temperature $(90 \stackrel{\circ}{\circ})$, and intermediate screw speed (233 rpm). The gluten-free snacks produced under these conditions were also found to have good sensory acceptance. The percentages of "like" responses were 73\% and "dislike" options were $19 \%$. The options "like extremely" and "dislike extremely" were not marked by the tasters in the global acceptance of the product (Figure 2). The choice of healthy food depends not only on the nutritional content but also on personal sensory preferences i.e., color, aroma, flavor, and texture, in addition to psychological and social considerations. 


\section{Materials and methods}

\section{Sample preparation and characterization}

Samples of cassava starch and rice flour were characterized for chemical composition in accordance with AACCI methods. Moisture: method 44-15.02, protein: method 4610.01, crude fat method 30-25.01, ash: method 08-12.01, and total fiber: method 32-10.01 (AACC, 2015). Total carbohydrates were determined by the phenol-sulfuric acid method (Adebooye and Singh, 2008). Cassava starch and rice flour mixtures were prepared, and the moisture content was adjusted to the experimental design (Table 1). After homogenization in a " $Y$ " homogenizer (Tecnal, TE201/5, Piracicaba, Brazil) for $5 \mathrm{~min}, 30$ samples of $1 \mathrm{~kg}$ each were set aside. The samples were transferred to closed containers and stored overnight at $4^{\circ} \mathrm{C}$ for equilibration before extrusion. The raw materials were also analyzed for color parameters, WSI, WAI, and pasting properties. Color measurements were performed using a Minolta CR-400 colorimeter (Konica Minolta, Ramsey, NJ, USA). The evaluation was based on CIELab. In this system, L* represents the lightness, which varies from zero (black) to 100 (white). $a^{*}$ and $b^{*}$ represent chromatic coordinates, where $+a^{*}$ indicates tendency to red and $-a^{*}$ indicates tendency to green; $+b^{*}$ indicates tendency to yellow, and $b^{*}$ indicates tendency to blue (Trombini et al., 2016).

The WAI and WSI were determined according to the method described by Anderson et al. (1969). The pasting properties of cassava starch and rice flour were evaluated using Rapid Visco Analyser (RVA), series 4, Newport Scientific (Warriewood, NSW, Australia), method extrusion 2. We used $3.5 \mathrm{~g}$ of the sample in $25 \mathrm{~mL}$ of water corrected to $140 \mathrm{~g} \mathrm{~kg}^{-1}$ wet basis (Leonel et al., 2009). All analyzes of raw materials were carried out in triplicate.

\section{Extrusion process}

Extrusion was carried out using a complete line of INBRARX (Inbramaq, Ribeirão Preto, Brazil) with a single screw, 130 $\mathrm{mm}$ barrel diameter, $440 \mathrm{~mm}$ extruder length, a hydraulic cooling system for temperature control, and $50 \mathrm{~kg} \mathrm{~h}^{-1}$ capacity. The constant parameters in the extrusion process were as follows: temperature in the $1^{\text {st }}\left(25^{\circ} \mathrm{C}\right)$ and $2^{\text {nd }}$ zones $\left(45^{\circ} \mathrm{C}\right)$, screw compression ratio $(3: 1)$, screw diameter $(19$ $\mathrm{mm})$, die diameter $(3 \mathrm{~mm})$, feed rate $\left(80 \mathrm{~g} \mathrm{~min}^{-1}\right)$, and cutting speed $(90 \mathrm{rpm})$. To evaluate the combined effect of the independent variables (cassava starch, raw material moisture content, temperature in the $3^{\text {rd }}$ extruder zone, and screw speed) on the dependent variables (REI, SV, hardness $(\mathrm{H})$, color ( $\mathrm{L}^{*}, \mathrm{a}^{*}$ and $\left.\mathrm{b}^{*}\right), \mathrm{WSI}$, and WAI), a $2^{\text {nd }}$ order central composite rotational design (CCRD) was used. A $2^{4}$ factorial design was used composed of 30 assays: 16 factorial points (combinations of levels -1 and +1 ); 8 axial points (one variable at level $+\alpha$ and three at 0 ; and one variable at level $-\alpha$ and three at 0 ); and 6 central points (all four independent variables at level 0 ) (Table 3 ). The upper and the lower limits of the variables were set based on the preliminary tests.

During the extrusion process, a portion of the next test material was used to purge the extruder. $500 \mathrm{~g}$ of the extruded sample was collected after achieving steady-state flow in the extruder. After extrusion, the samples were dried $\left(40{ }^{\circ} \mathrm{C}\right)$ to the desired moisture level $(6 \%$ to $7 \%)$ in an air circulation oven MA037 (Marconi, Piracicaba, Brazil). The extrudates were packaged, and the samples were stored at 4 ${ }^{\circ} \mathrm{C}$ until analysis.

\section{Analysis of extruded snacks}

The REI was evaluated after extrusion and before drying, using a digital caliper. The REI indexes were derived from the division of the radial expansion by the die orifice diameter ( 3 $\mathrm{mm}$ ). The measurement was repeated 20 times on each sample (Spinello et al., 2014). The SV was determined according to the mass displacement method (millet seed) using a graded pipette (Spinello et al., 2014). Three measurements were performed for each treatment. The $\mathrm{H}$ values of the samples were determined using a texture analyzer TA-XT2 (Stable Micro Systems, Surrey, England) with a 50-kg load cell and a probe HDP/WBV (Warner Bratzler set with "V" slot blade for USDA Standard). The conditions used in the hardness analysis were as follows: measurement of force in compression; force threshold of 1.0 $\mathrm{g}$; pre-test speed of $4.0 \mathrm{~mm} \mathrm{~s}^{-1}$; test speed of $1.0 \mathrm{~mm} \mathrm{~s}^{-1}$; and post-test speed of $5.0 \mathrm{~mm} \mathrm{~s}^{-1}$; rupture distance of $15 \mathrm{~mm}$. Three measurements were performed in each treatment (Spinello et al., 2014). After these measurements, the extruded samples were milled to a mean particle size of approximately $150 \mu \mathrm{m}$. The milled samples were analyzed for color, WSI, and WAI, as previously described for the raw materials.

\section{Sensory acceptance}

After optimizing the process conditions that yielded snacks with the desired characteristics of expansion, density, crispness, color, WAl, and WSI, we performed another process under these experimental condition (10\% cassava starch in the rice flour mixture, $14 \%$ moisture, 90 ㅇ temperature, and $233 \mathrm{rpm}$ ). The obtained products were flavored with salt, monosodium glutamate, cheese flavor, and hydrogenated vegetable fat and evaluated for global acceptance using a hedonic scale of 9 points. The 9-point hedonic scale is a balanced bipolar scale around neutral at the center, with four positive and four negative categories on each side (Lim, 2011). The global acceptance of the snacks was evaluated by 100 untrained judges ( 50 men and 50 women aged 18 to 27 years).

\section{Statistical analysis}

Response surface methodology describes the behavior of a system in which the independent variables $\left(X_{k}\right)$ and the dependent variable or response $\left(Y_{i}\right)$ are combined. The response is a function of the levels at which these factors are combined and defined. The model is fitted by the option "step-wise" of the SAS program; the obtained model is evaluated through the F-test using the pure error mean square as denominator. The response surfaces plots were drawn from the adjusted models using the software Statistica ${ }^{\circledR} 6.0$ (Stat Soft, Inc., Tulsa, USA).

\section{Conclusion}

Cassava starch and rice flour have physicochemical properties favorable for the production of gluten-free 
snacks. Among the variable parameters concerning the extrusion process, the percentage of cassava starch mixed with rice flour has a greater impact on the product properties, while screw speed has less impact. Snacks with high expansion, low density, lower hardness, light color, low solubility, and good sensory acceptance are obtained under conditions of low cassava starch percentage, low moisture, low temperature, and intermediate screw speed.

\section{Acknowledgement}

The authors would thank to the Coordination for the Improvement of Higher Education Personnel (CAPES) to scholarship granted for the master's degree studies of the second author, and the National Council for Scientific Technological Research (CNPq) for financial support

\section{References}

AACC International (2015) Approved Methods of Analysis, 11th ed. Methods 08-01.01 Ash-Basic Method; 44-15.02 Moisture-Air-Oven Methods; 46-30.01 Crude ProteinCombustion Method; 76-13.01 Total Starch Assay Procedure (Megazyme Amyloglucosidase/alpha-Amylase Method). Available in: <http://methods.aaccnet.org/default.aspxx>, accessed in 2015 May.

Adebooye OC, Singh V (2008) Physico-chemical properties of the flours and starches of two cowpea varieties (Vigna unguiculata (L.) Walp). Innov Food Sci Emerg 9: 92-100.

Allen KE, Carpenter CE, Walsh MK (2007) Influence of protein level and starch type on an extrusion-expanded whey product. IJFST 42 (8): 953-960.

Anderson RA, Conway H, Pfeifer VF, Griffin EL (1969) Gelatinization of corn grits by roll and extrusion cooking. Cereal Sci Today 14: 4-12.

Ashogbon AO, Akintayo ET (2012) Morphological, functional and pasting properties of starches separated from rice cultivars grown in Nigeria. IFRJ 19(2): 665-671.

Arendt EK, Nunes MHB (2010) Processing gluten-free foods. In: Boye Jl, Godefroy SB (Eds.) John Wiley and Sons, Allergen Management in the Food industry. New Jersey: Hoboken Inc.

Awolu OO, Oluwaferanmi PM, Fafowora OI, Oseyemi GF (2015) Optimization of the extrusion process for the production of ready-to-eat snack from rice, cassava and kersting's groundnut composite flours. LWT-Food Sci Technol 64: 18-24.

Berk Z (2009) Extrusion. Food process engineering and technology. London: Academic Press

Chang YK, El-Dash AA (2003) Effects of acid concentration and extrusion variables on some physical characteristics and energy requirements of cassava starch. Braz J Chem Eng 20(2): 129-137.

Clerici MTPS, El-Dash AA (2008) Technological properties of pre-gelatinized rice flour obtained by thermoplastic extrusion. Cienc Agrotec. 32(5): 1543-1550.

Ding QB, Ainsworth P, Tucker G, Marson H (2005) The effect of extrusion conditions on the physicochemical properties and sensory characteristics of rice-based expanded snacks. J Food Eng 66(3): 283-289.

Khush GS (2005) What it will take to feed 5.0 billion rice consumers in 2030. Plant Mol Biol. 59: 1-6.
Leonel M, Freitas TS, Mischan MM (2009) Physical characteristics of extruded cassava starch. Sci Agric. 66(4):486-493.

Leonel M, Souza LB, Mischan MM (2011) Thermal and pasting properties of cassava starch-dehydrated orange pulp blends. Sci Agric. 68(3): 342-346.

Lim J (2011) Hedonic scaling: A review of methods and theory. Food Qual Prefer 22:733-747.

Masure HG, Fierens E, Delcour JA (2016) Current and forward looking experimental approaches in gluten-free bread making research. J Cereal Sci 67: 92-111.

Masatcioglu MT, Yalcin E, Hwan PJ, Ryu G-H, Celik S, Koksel H (2014) Hull-less barley flour supplemented corn extrudates produced by conventional extrusion and $\mathrm{CO} 2$ injection process. Innov Food Sci Emerg 26: 302-309.

Meng X, Threinen D, Hansen M, Driedger D (2010) Effects of extrusion conditions on system parameters and physical properties of a chickpea flour based snack. Food Res Int 43(2): 650-658.

Mesquita CB, Leonel M, Mischan MM (2013) Effects of processing on physical properties of extruded snacks with blends of sour cassava starch and flaxseed flour. Food Sci Technol. 33 (3): 404-410.

Moraru Cl, Kokini JL (2003) Nucleation and expansion during extrusion and microwave heating of cereal foods. CRFSFS 2(4): 147-163.

Onitilo MO, Sanni LO, Daniel I, Maziya-Dixon (2007) Physicochemical and functional properties of native starches from cassava varieties in Southwest Nigeria. JFAE 5(3-4): 108-114.

Salata CC, Leonel M, Trombini FRM, Mischan MM (2014) Extrusion of blends of cassava leaves and cassava flour: Physical characteristics of extrudates. Food Sci Technol. 34(3): 501-514.

Setyawati YD, Ahsan SF., Ong LK, Soetaredjo FE, Ismadji S, Ju Y-H (2016) Production of glutinous rice flour from broken rice via ultrasonic assisted extraction of amylose. Food Chem. 203: 158-164.

Spinello AM, Leonel M, Mischan MM, Carmo EL (2014) Cassava and turmeric flour blends as new raw materials to extruded snacks. Cienc Agrotec. 38: 68-75.

Sumargo F, Gulati P, Weier SA, Clarke J, Rose DJ (2016) Effects of processing moisture on the physical properties and in vitro digestibility of starch and protein in extruded brown rice and pinto bean composite flours. Food Chem. 211:726-733.

Taverna LG, Leonel M, Mischan MM (2012) Changes in physical properties of extruded sour cassava starch and quinoa flour blend snacks. Food Sci Technol. 32(4): 826834.

Ti H, Zhang R, Zhang M, Wei Z, Chi J, Deng Y, Zhang Y (2015) Effect of extrusion on phytochemical profiles in milled fractions of black rice. Food Chem. 178: 186-194.

Thymi S, Krokida MK, Pappa A, Maroulis ZB (2005) Structural properties of extruded corn starch. J Food Eng 68: 519526.

Tong C, Liu L, Waters DLE, Huang Y, Bao J (2015) The contribution of lysophospholipids to pasting and thermal properties of non waxy rice starch. Carbohydr Polym. 133: 187-193.

Torbica A, Hadnadev M, Dapcevic T (2010) Rheological, textural and sensory properties of gluten-free bread 
formulations based on rice and buckwheat flour. Food Hydrocolloid 24: 626-632.

Trombini FRM, Leonel M, Mischan MM (2016) Instant blend from cassava derivatives produced by extrusion. Cienc Rural 46(3): 573-579.

Vargas-Solórzano JW, Carvalho CWP, Takeiti CY, Ascheri JLR, Queiroz VAV (2014) Physicochemical properties of expanded extrudates from colored sorghum genotypes. Food Res Int 55: 37-44.

Wang L, Duan W, Zhou S, Qian H, Zhang H, Qi X (2016) Effects of extrusion conditions on the extrusion responses and the quality of brown rice pasta. Food Chem. 204: 320325.

Wanyo P, Channarong-Chomnawang C, Siriamornpun S (2009) Substitution of wheat flour with rice flour and rice bran in flake products: Effects on chemical, physical and antioxidant properties. WASJ 7(1): 49-56.
Witczak M, Ziobro R, Juszczak L, Korus J (2016) Starch and starch derivatives in gluten-free systems- a review. J Cereal Sci 67: 46-57.

Wu F, Meng Y, Yang N, Tao H, Xu X (2015) Effects of mung bean starch on quality of rice noodles made by direct dry flour extrusion. LWT - Food Sci Tech 63: 1199-1205.

Yan CJ, Li X, Zhang R, Sui JM, Liang GH, Shen XP, Gu SI, Gu $\mathrm{MH}$ (2005) Performance and inheritance of rice starch RVA profile characteristics. Rice Science 12(1): 39-47.

Yu S, Ma Y, Menager L, Sun DW (2012) Physicochemical properties of starch and flour from different rice cultivars. Food Bioprocess Technol 5: 626-637.

Zhu F (2015) Composition, structure, physicochemical properties and modifications of cassava starch. Carbohydr Polym 122: 456-480. 